\title{
Peta Isochrone Sebagai Identifikasi Kualitas Akses Bandara: Studi kasus Bandara Internasional Juanda
}

\author{
Rizky Fitri Amalia Istighfaroh ${ }^{1}$, Ervina Ahyudanari ${ }^{1, *}$, Nursakti Adhi Pratomoatmojo ${ }^{2}$ \\ Departemen Teknik Sipil, Institut Teknologi Sepuluh Nopember, Surabaya ${ }^{1}$, Departemen Perencanaan Wilayah dan Kota, Institut Teknologi \\ Sepuluh Nopember, Surabaya ${ }^{2}$ \\ Koresponden*, Email: ervina@ce.its.ac.id
}

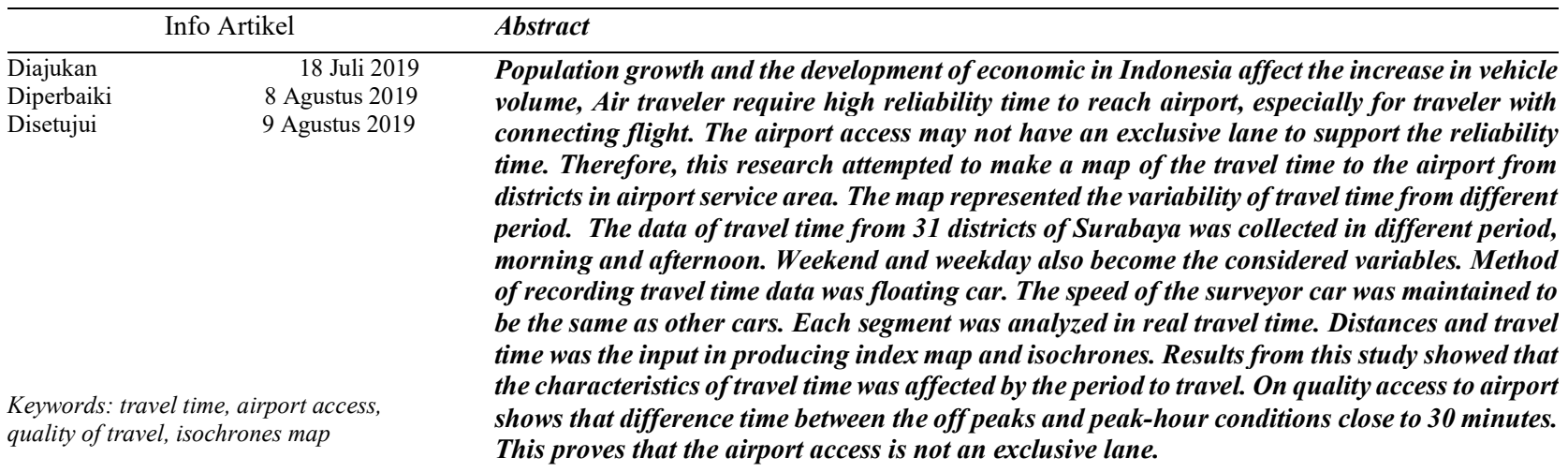

\begin{abstract}
Abstrak
Penumpang pesawat membutuhkan relibility yang tinggi untuk mencapai bandara, terutama bagi penumpang dengan penerbangan lanjutan. Akses bandara mungkin tidak memiliki jalur eksklusif untuk mendukung reliability. Oleh karena itu, penelitian ini berusaha membuat peta waktu tempuh ke bandara dari kecamatan di area layanan bandara. Peta mewakili variabilitas waktu perjalanan dari periode yang berbeda. Data waktu perjalanan dari 31 kecamatan Surabaya dikumpulkan dalam periode yang berbeda, pagi dan sore. Akhir pekan dan hari kerja juga menjadi variabel yang dipertimbangkan. Metode pencatatan data waktu tempuh adalah running speed. Kecepatan mobil surveyor dipertahankan sama dengan mobil lain. Setiap segmen dianalisis dalam waktu perjalanan nyata. Jarak dan waktu tempuh adalah input dalam menghasilkan peta indeks dan isochrones. Hasil dari penelitian ini menunjukkan bahwa karakteristik waktu perjalanan dipengaruhi oleh periode untuk bepergian. Pada kualitas akses ke bandara menunjukkan bahwa perbedaan waktu antara puncak dan kondisi jam puncak mendekati 30 menit. Ini membuktikan bahwa akses bandara bukan jalur eksklusif.
\end{abstract}

\section{Pendahuluan}

Bandara Internasional Juanda adalah daerah yang memberikan daya tarik pada pergerakan transportasi di Surabaya, sehingga mode akses bandara juga berkontribusi terhadap kepadatan lalu lintas. Dengan asumsi jika pada jam sibuk jumlah penumpang di bandara Juanda mencapai 2000 lebih ini berarti aktivitas di bandara meningkatkan sekitar 2000 mobil pribadi di jalan raya.

Perjalanan ke bandara (akses) dimulai ketika penumpang meninggalkan rumah dan memulai perjalanan ke bandara. Waktu kedatangan penumpang di bandara salah satunya dipengaruhi oleh kondisi aksesibilitas ke bandara. Oleh karena itu, dalam mempersiapkan proses perjalanan, penumpang akan menghitung mundur dari waktu keberangkatan pesawat, ditambah perkiraan waktu perjalanan dari kecepatan kondisi aksesibilitas perjalanan, sehingga diperoleh rentang waktu yang aman di mana penumpang harus berangkat dari rumah ke bandara. dengan waktu tanpa khawatir datang terlambat[1]

Perkembangan kota yang dilayani oleh bandara sangat mempengaruhi permintaan bandara. Bandara Juanda menunjukkan jumlah pertumbuhan penumpang 16\% per tahun di mana 13\%[2] adalah penumpang dari Surabaya. Tingginya tingkat pertumbuhan penumpang meningkatkan kepadatan lalu lintas di jalan akses ke Juanda. Kenyamanan ke bandara Juanda telah difasilitasi oleh jalan tol Waru Juanda, tetapi akses ke jalan tol ini masih harus 
menggunakan jalan akses yang sudah ada yang memiliki kepadatan tinggi pada jam sibuk ketika pergi ke Juanda.

Kepadatan jalan akses yang tinggi telah menyebabkan peningkatan waktu perjalanan ke bandara. Untuk mengetahui perbedaan waktu ideal dan waktu perjalanan selama jam sibuk di rute ke bandara, dilakukan studi realibilitas waktu perjalanan ke bandara juanda. Tujuan dari penelitian ini adalah untuk mengetahui waktu yang signifikan antara kondisi normal dan kondisi sibuk[3].

Karena pola perjalanan yang berbeda, ada juga perbedaan tren dengan waktu kedatangan penumpang di bandara. Secara umum, untuk penumpang yang berada sangat jauh dari bandara atau yang kondisi perjalanannya tidak dapat diprediksi, waktu yang lebih aman akan diambil ketika berangkat dari rumah, sehingga risiko tiba terlambat di bandara dapat diminimalkan[4]. Perbandingan perubahan waktu perjalanan udara darat ditunjukkan seperti pada Gambar 1.

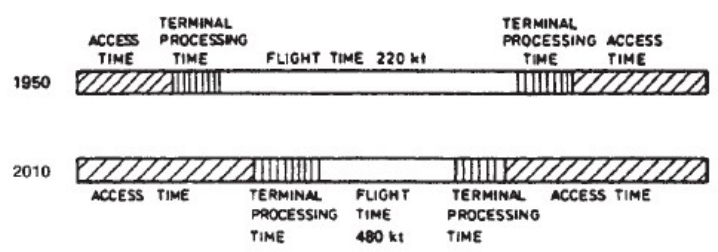

Gambar 1. Perbandingan Perubahan Waktu Perjalanan Udara

Maskapai menggabungkan akses waktu perjalanan realistis ke bandara pada jadwal yang dipublikasikan. Informasi yang disediakan oleh maskapai membantu para penumpang pesawat untuk memperkirakan waktu dan biaya perjalanan mereka. Preferensi ini mempengaruhi pemilihan bandara untuk melayani penerbangan mereka. Area tangkapan bandara juga menentukan kualitas akses bandara, terutama jika akses bercampur dengan rute lain. menemukan bahwa perjalanan non-aeronautika mempengaruhi kualitas akses ke bandara. Para peneliti ini sepakat bahwa kualitas akses ke bandara perlu perbaikan melalui beberapa teknik. Faktor yang paling penting agar penumpang udara tidak ketinggalan penerbangan karena waktu perjalanan yang tidak terduga[1].

\section{Metode}

Penentuan Zona dan Trip Generation

Daerah tarikan bandara menjadi variabel dalam penelitian ini. Penentuan zona asal penumpang pesawat dan proses pemilihan rute juga mengidentifikasi ruang lingkup penelitian dan batasan masalah. Dalam penentuan zona menggunakan administrasi kota Surabaya, dan pusat zona berdasarkan perumahan kelas menengah atas, pusat perbelanjaan, universitas, daerah wisata dan fasilitas transportasi umum. Pusat zona akan digunakan dalam menganalisis variasi waktu tempuh dari setiap kecamatan ke rute yang dipilih[5].

Penentuan rute akses ke bandara terbatas untuk meninjau kelas jalan arteri dan kolektor. Setelah memetakan rute, running speed survey dilakukan untuk mendapatkan kecepatan sebenarnya dari setiap rute akses ke Bandara Internasional Juanda. Perhitungan jalan perkotaan dilakukan dengan membagi setiap ruas untuk mendapatkan waktu tempuh per ruas.

\section{Mengukur Waktu Perjalanan dengan Mobil}

Teknik pengujian kendaraan telah digunakan untuk perjalanan waktu pengumpulan data sejak akhir 1920-an. Secara tradisional, teknik ini telah melibatkan penggunaan pengumpulan data kendaraan di mana pengamat mencatat waktu perjalanan kumulatif pada pos pemeriksaan yang ditentukan sebelumnya di sepanjang rute perjalanan. Informasi ini kemudian diubah menjadi waktu tempuh, kecepatan, dan penundaan untuk setiap segmen di sepanjang rute survei. Ada beberapa metode berbeda untuk melakukan pengumpulan data jenis ini, tergantung pada survei yang digunakan dalam kendaraan dan instruksi mengemudi yang diberikan kepada pengemudi.

Dalam tes ini dijelaskan tiga tingkat instrumentasi yang digunakan untuk mengukur waktu perjalanan dengan kendaraan uji: [2]

- Waktu rekam manual berlalu di pos pemeriksaan yang telah ditetapkan menggunakan penumpang di kendaraan uji;

- Distance Measure (DMI) - menentukan waktu perjalanan sepanjang koridor berdasarkan kecepatan dan jarak informasi yang disediakan oleh DMI elektronik yang terhubung ke transmisi kendaraan uji; dan

- Global Positioning System (GPS) - menentukan tes dan kecepatan posisi kendaraan dengan menggunakan sinyal dari Departemen Pertahanan (DOD) sistem satelit yang mengorbit Bumi.

Dalam penelitian ini, data primer dikumpulkan dari survei jalan arteri dan kolektor di Surabaya. Pengumpulan data adalah sampel pada jam sibuk. Pada rute yang disurvei untuk menghitung durasi perjalanan kondisi nyata di setiap rute, survei dilakukan oleh mobil pribadi, 2 orang surveyor dan selama lima hari Senin, Rabu, Jumat, Sabtu dan Minggu pengambilan sampel data jam puncak pagi dan sore kecuali pada hari Minggu sekali sehari karena hari bebas mobil. dengan total 5 rute di Surabaya barat diasumsikan memasuki 
tol dan 5 rute utama ke Juanda melalui jalan arteri primer dan arteri sekunder total sampel adalah 90. [7]

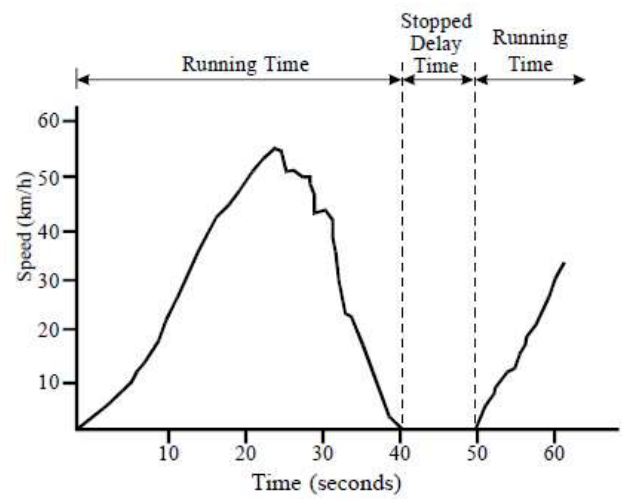

Gambar 2. Profil kecepatan

\section{Hasil dan Pembahasan}

Variasi travel time dari masing-masing kecamatan

Dari data total perjalanan waktu riil di pagi dan sore hari setiap kecamatan yang tercantum dalam Gambar 3, menunjukkan bahwa variasi waktu perjalanan di kecamatan Surabaya dapat dilihat bahwa waktu perjalanan di sore hari lebih panjang dari pagi hari. Hal ini karena pada pagi hari tarikan ke Surabaya lebih besar daripada di luar Surabaya, sedangkan Bandara Juanda secara administratif terletak di Sidoarjo, sehingga pada sore hari akses objek wisata ke Bandara Juanda lebih panjang daripada di pagi hari. Perbedaan waktu antara siang dan pagi di hampir semua distrik juga menunjukkan perbedaan yang signifikan antara 30 dan 50 menit.

Karakteristik waktu perjalanan pada setiap rute akan dilihat dari segi jarak dan waktu yang berbeda diplotkan hasil survei komparatif antara waktu tempuh dengan pilihan rute, total pengambilan sampel data 5 hari, interval waktu pengumpulan data di pagi dan sore hari. Pengambilan data juga melihat waktu jam variasi segmen jalan Surabaya dapat dilihat pada Gambar 4 sampai 6 yang merupakan perbandingan waktu perjalanan dan jarak.

Hasil analisis ini ditemukan pada jarak $15 \mathrm{Km}$ hingga 30 $\mathrm{Km}$ dari bandara terdapat banyak variasi waktu perjalanan ini menunjukkan di zona ada banyak pilihan rute alternatif dengan kepadatan lalu lintas yang tinggi di zona. Sebaliknya pada jarak $35 \mathrm{~km}$ hingga $50 \mathrm{~km}$ variasi waktu tempuh menyusut ini disebabkan lokasi bandara Juanda yang terletak di sebelah selatan Surabaya dimana secara administratif Juanda masuk ke Kabupaten Sidoarjo sehingga jarak terjauh dari Juanda adalah asem rowo, benowo, dan zona pakal di mana di zona ini sebagian besar memiliki pergudangan penggunaan lahan sehingga tidak banyak area perumahan di zona tersebut sehingga waktu perjalanan di zona ini lebih rendah daripada waktu perjalanan lainnya. Pada Gambar 4 kita memiliki rentang waktu perjalanan yang berbeda walaupun mereka memiliki jarak yang sama, hari yang sama tetapi waktu yang berbeda

Karakteristik waktu perjalanan pada setiap rute akan dilihat dari segi jarak dan waktu yang berbeda diplotkan hasil survei komparatif antara waktu tempuh dengan pilihan rute, total pengambilan sampel data 5 hari, interval waktu pengumpulan data di pagi dan sore hari. Pengambilan data juga melihat waktu jam variasi jalan segmen Surabaya dapat dilihat pada Gambar 4 sampai 5 yang merupakan perbandingan waktu perjalanan dan jarak.

Hasil analisis ini ditemukan pada Gambar $\mathbf{4}$ dan 5 jarak tidak berpengaruh signifikan terhadap waktu tempuh dari masing-masing kecamatan yang ditunjukkan oleh R2 yaitu $0,335,0,3797$, dan 0,0845. Ini berarti variabel lain waktu perjalanan, dapat disebabkan ada banyak faktor yang menyebabkan nonlinier ini, termasuk ketersediaan rute, jalan padat, pencampuran lalu lintas akses bandara dengan lalu lintas lainnya, dan lokasi bandara Juanda yang terletak di sebelah selatan Surabaya dimana secara administratif Juanda masuk ke Kabupaten Sidoarjo sehingga daya tarik pada malam hari lebih besar dari pagi hari menyebabkan orang bekerja di Surabaya dan tinggal di Sidoarjo.

\section{Kualitas Perjalanan Setiap rute}

Kualitas perjalanan pada setiap rute akan ditampilkan pada peta isochrone dan indeks waktu perjalanan dari terminal 1 bandara Juanda. Kualitas Perjalanan pertama ditunjukkan dengan indeks waktu tempuh peta. Peta ini menunjukkan perbandingan antara waktu perjalanan riil dibagi dengan waktu perjalanan rencana di mana waktu perjalanan rencana diperoleh dari perbandingan setiap jarak jalan dibagi dengan kecepatan yang diperoleh sesuai dengan kelas. jalan sehingga semakin besar jumlah perbandingan antara keduanya yang menunjukkan semakin tinggi kemacetan ruas jalan.

Peta Isochrone disajikan dalam berbagai hari dan setiap hari digambarkan sebagai jam sibuk dan kondisi minimum. Kondisi jam sibuk adalah kondisi di mana pada jam itu kondisi volume jalan paling penuh, dan kondisi minimum adalah kondisi di mana volume jalan paling terbuka. Pada Gambar 6 menunjukkan kondisi waktu puncak jam perjalanan memiliki 13 warna berbeda di mana warna akan menunjukkan bahwa waktu perjalanan pada jam puncak untuk mencapai kecamatan terjauh dari bandara Juanda membutuhkan waktu 130 menit untuk mencapai Benowo dan kecamatan Pakal membutuhkan waktu 130 menit. Kemudian 
pada Gambar 9 menunjukkan waktu tempuh nyata pada hari Senin dengan kondisi minimum perbedaan warna yang signifikan ada 10 warna pada peta waktu tempuh nyata dengan kondisi minimum kecamatan terjauh, yaitu kecamatan pakal hanya 100 menit.

Pada peta isochrone menunjukkan hasil analisis yang berbeda dengan pembahasan karakteristik waktu tempuh dibandingkan dengan jarak sebelumnya, dalam pembahasan karakteristik waktu tempuh dengan jarak ditemukan fakta bahwa pada jarak terjauh tidak menunjukkan waktu tempuh terpanjang sedangkan sebaliknya pada peta isochrone, hal ini disebabkan karena analisis karakteristik ruas jalan rujukan adalah jalan pada rute yang dipilih sehingga pada rute di Surabaya barat diasumsikan memasuki jalan tol memiliki perjalanan yang lebih pendek waktu. Sedangkan peta isochrone dalam proses pembuatannya menggunakan perangkat lunak tambahan Arcgis di mana pemilihan rute dipilih oleh Arcgis dengan banyak kemungkinan sehingga waktu perjalanan akan lebih lama.

Jadi dari dua parameter kualitas perjalanan yaitu peta waktu perjalanan menunjukkan pada opsi rute bebarapa ruas jalan memiliki indeks yang ekstrim, terutama di jalan Ahmad Yani ke Waru ke Juanda yang merupakan jalan utama menuju Bandara Juanda dan peta isochrone menunjukkan perbedaan yang signifikan antara kondisi minimum dan kondisi jam puncak hingga 30 menit ini membuktikan bahwa bandara memiliki daya tarik besar pada pergerakan transportasi di Surabaya, sehingga penumpang bandara perlu memperhatikan proses perjalanan darat dari proses perjalanan udara

\section{Simpulan}

Karakteristik waktu tempuh berdasarkan jarak umumnya menunjukkan bahwa jarak terpanjang tidak menunjukkan waktu tempuh terpanjang karena jarak terjauh di Surabaya Barat dapat diatasi melalui jalan tol menuju Bandara Juanda sehingga pada jarak $20 \mathrm{~km}$ hingga $30 \mathrm{~km}$ adalah waktu perjalanan terpanjang. Kualitas akses perjalanan ke bandara yang ditunjukkan pada peta waktu perjalanan menunjukkan rute yang dipilih, beberapa jalan memiliki indeks ekstrim, terutama pada jalan Ahmad Yani ke Waru ke Juanda yang merupakan jalan utama ke Bandara Juanda dan Peta isochrone menunjukkan perbedaan waktu yang signifikan antara kondisi minimum dan kondisi jam puncak hingga 30 menit, ini membuktikan bahwa bandara memiliki daya tarik besar untuk pergerakan transportasi di Surabaya, sehingga penumpang bandara perlu mempertimbangkan proses perjalanan darat daripada perjalanan udara.

\section{Daftar Pustaka}

[1] M. L. Tam, W. H. K. Lam, and H. P. Lo, "The impact of travel time reliability and perceived service quality on airport ground access mode choice," J. Choice Model., vol. 4, no. 2, pp. 49-69, 2011.

[2] Y. E. Rahayu, E. Ahyudanari, and N. A. Pratomoadmojo, "Land Use Development and its Impact on Airport Access Road," Procedia - Soc. Behav. Sci., vol. 227, no. November 2015, pp. 31-37, 2016.

[3] P. Koster, E. Kroes, and E. Verhoef, "Travel time variability and airport accessibility," Transp. Res. Part B Methodol., 2011.

[4] M. A. Coogan, Ground Access to Major Airports by Public Transportation. 2008.

[5] D. O'Sullivan, A. Morrison, and J. Shearer, "Using desktop GIS for the investigation of accessibility by public transport: An isochrone approach," Int. J. Geogr. Inf. Sci., vol. 14, no. 1, pp. 85-104, 2000.

[6] J. Rupnik, J. Davies, B. Fortuna, A. Duke, and S. S. Clarke, "Travel Time Prediction on Highways," 2015 IEEE Int. Conf. Comput. Inf. Technol. Ubiquitous Comput. Commun. Dependable, Auton. Secur. Comput. Pervasive Intell. Comput., pp. 1435-1442, 2015.

[7] M. B. Russell, "Travel Time Reliability and Level of Service," 2014. 
TRAVEL TIME SENIN

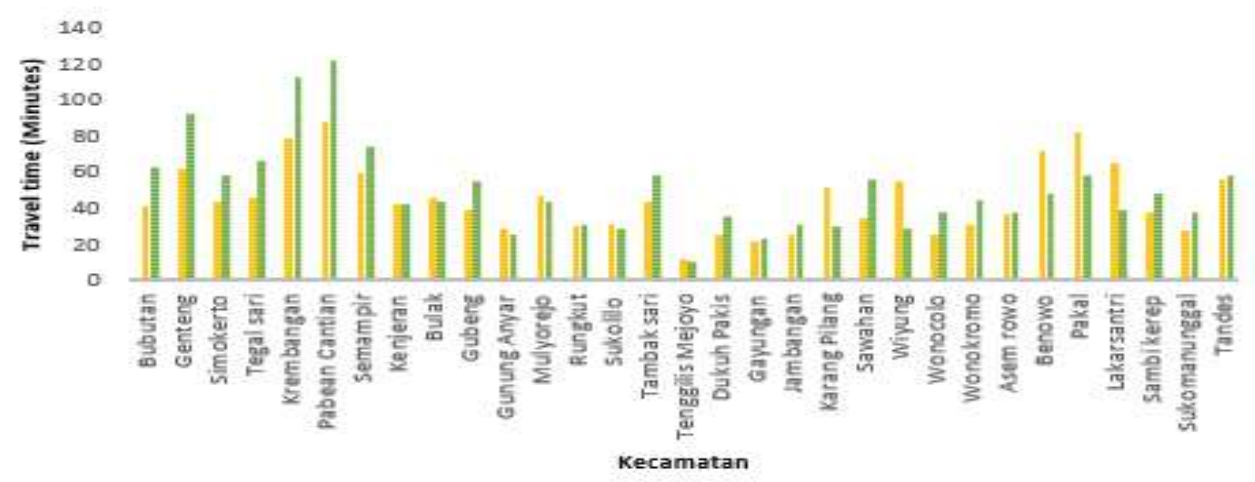

Gambar 3. Total Waktu Perjalanan Setiap Zona ke Bandara Juanda, Senin Senin

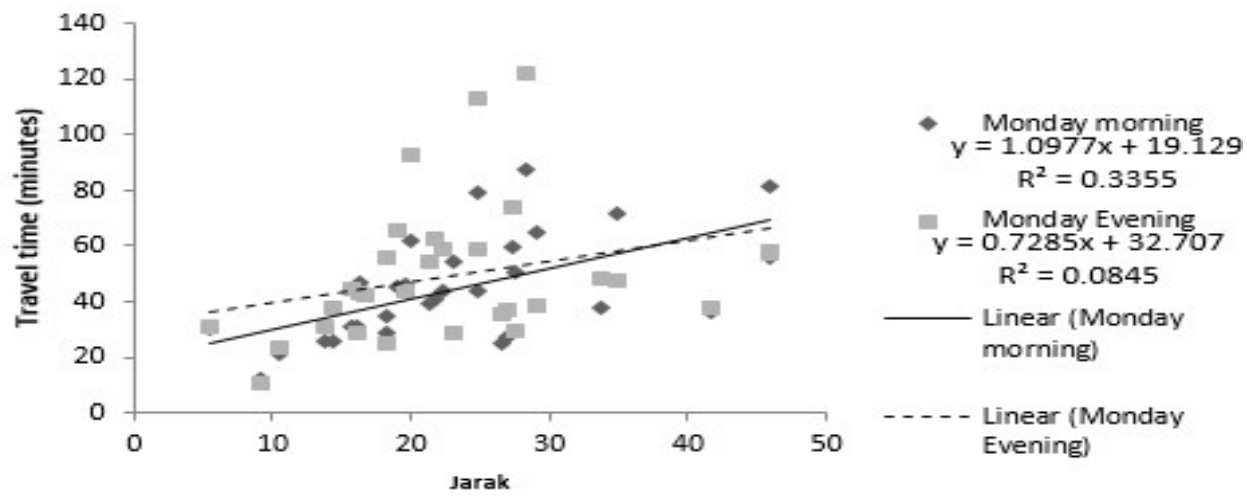

Gambar 4. Total Waktu Perjalanan Setiap Zona ke Bandara Juanda, Senin

\section{MINGGU}

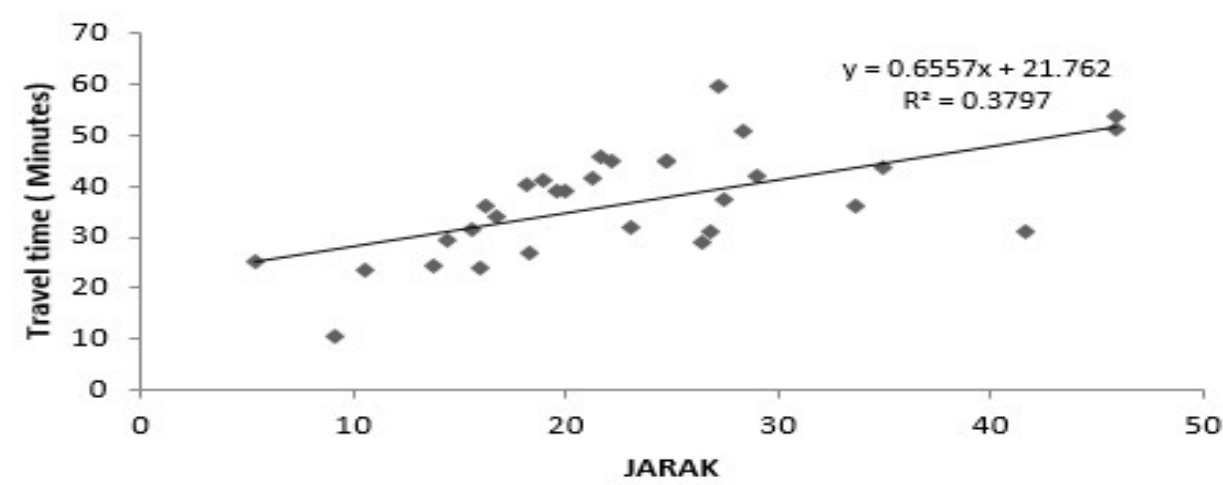

Gambar 5. Total Waktu Perjalanan Setiap Zona ke Bandara Juanda, Minggu 


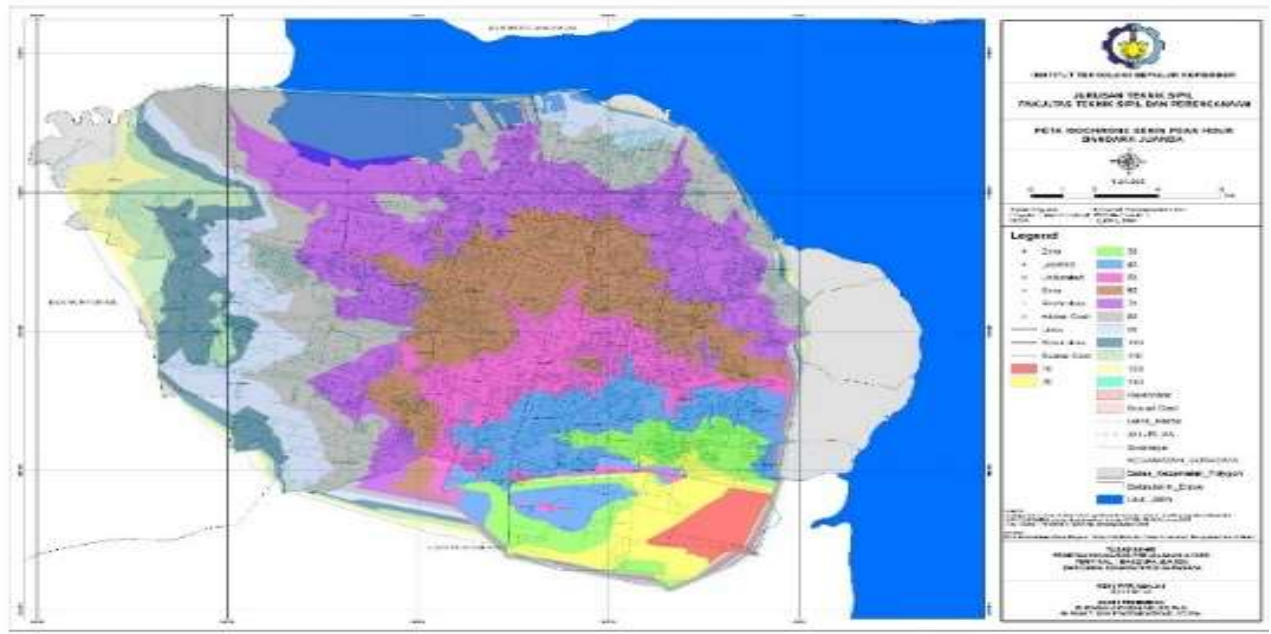

Gambar 6. Isochrone ke Bandara Juanda Senin Pagi

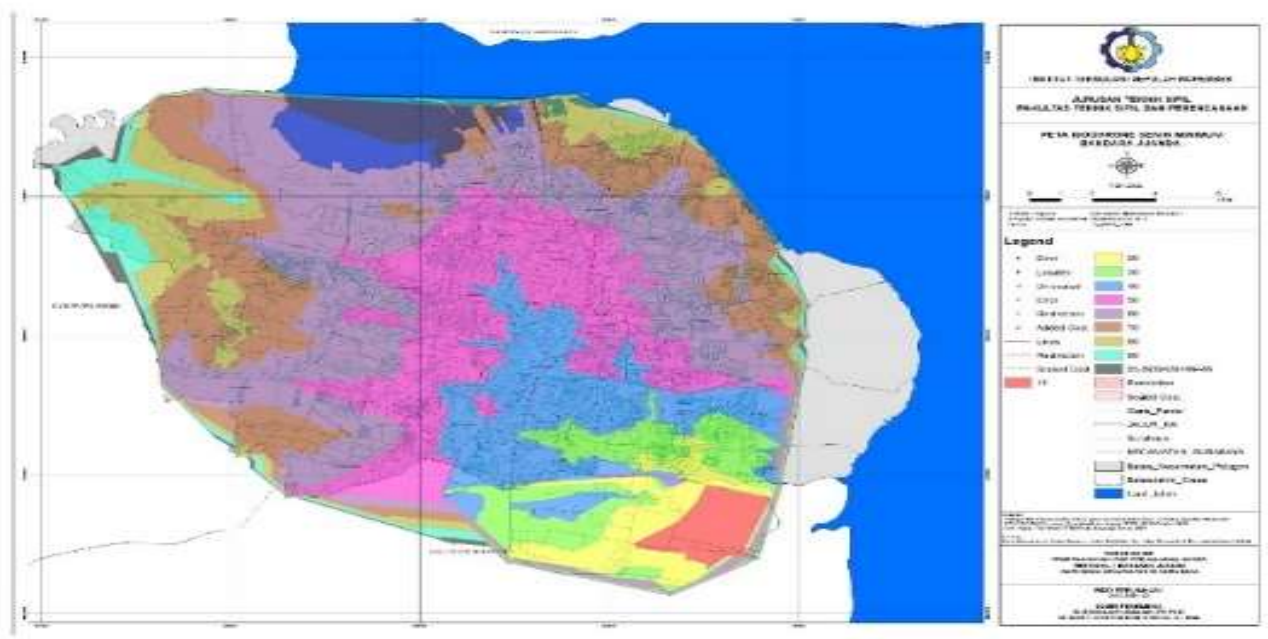

Gambar 7. Isochrone ke Bandara Juanda Senin Sore

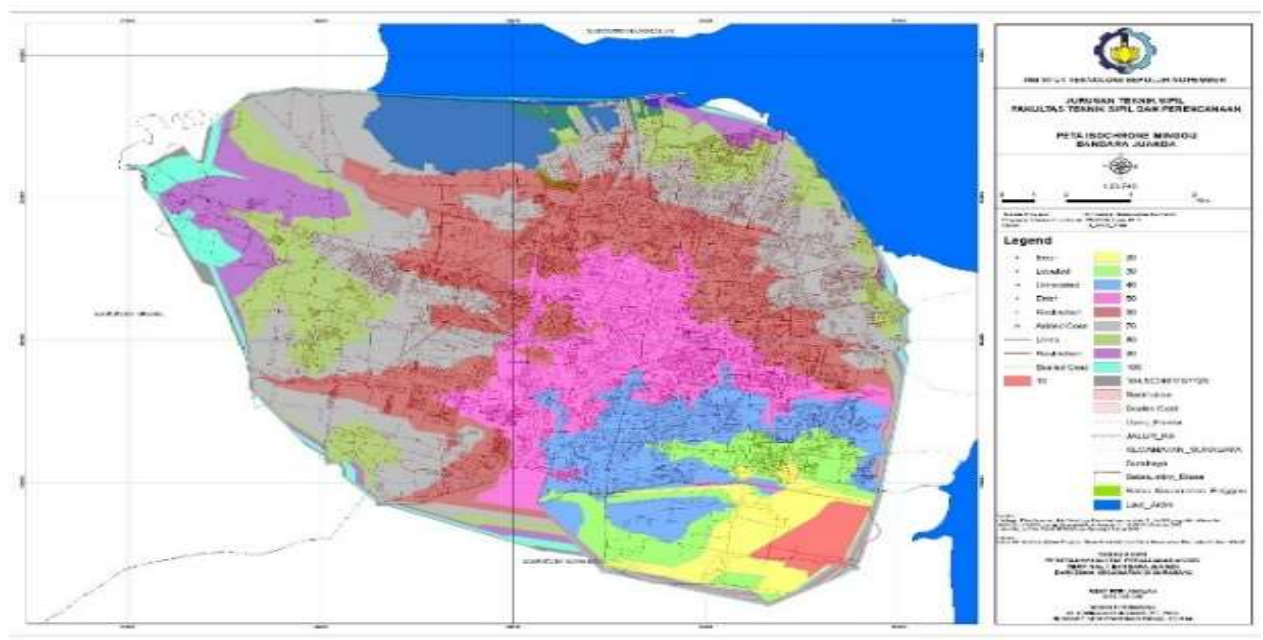

Gambar 8. Isochrone ke Bandara Juanda Minggu 